\title{
Development of a Novel Electrochemical Inhibition Sensor Array Based on Bacteria Immobilized on Modified Screen-Printed Gold Electrodes for Water Pollution Detection
}

\author{
H. Abu-Ali ${ }^{1,2}$ (D) A. Nabok ${ }^{1} \cdot$ T. J. Smith ${ }^{3} \cdot$ M. Al-Shanawa ${ }^{2}$
}

Published online: 7 March 2019

(C) The Author(s) 2019

\begin{abstract}
The development of a novel and simple inhibition biosensor array for detection of water pollutants based on bacteria immobilized on the surface of the electrodes is the main goal of this work. A series of electrochemical measurements (i.e., cyclic voltammograms) were carried out on modified screen-printed gold electrodes with three types of bacteria, namely Escherichia coli, Shewanella oneidensis, and Methylococcus capsulatus (Bath), immobilized via poly L-lysine. For comparison purposes, similar measurements were carried out on bacteria samples in solutions; also optical measurements (fluorescence microscopy, optical density, and flow cytometry) were performed on the same bacteria in both liquid and immobilized forms. The study of the effect of heavy metal ions (lead), pesticides (atrazine), and petrochemicals (hexane) on DC electrochemical characteristics of immobilized bacteria revealed a possibility of pattern recognition of the above inhibition agents in an aquatic environment.
\end{abstract}

Keywords Electrochemical sensor · Inhibition bacteria sensor array · Immobilization of bacteria $\cdot$ Water pollution $\cdot$ Pattern recognition

\section{Introduction}

Nowadays, heavy metals, pesticides, and petrochemicals possessing serious threat to humans and living organisms are of the main concern for the environmental security. The most common sources of environmental pollution are manufacturing, automotive, agricultural, chemical, and medical industries [1]. For instance, three of the most common heavy metals

\section{H. Abu-Ali}

b4039024@my.shu.ac.uk

\author{
A. Nabok \\ a.nabok@shu.ac.uk \\ T. J. Smith \\ scitjs@exchange.shu.ac.uk \\ M. Al-Shanawa \\ methem_aa@yahoo.com
}

1 Materials and Engineering Research Institute, Sheffield Hallam University, Sheffield, UK

2 Faculty of Science, University of Basrah, Basrah, Iraq

3 Biomolecular Research Centre, Sheffield Hallam University, Sheffield, UK released from road travel are zinc, copper, and lead, accounting for at least $90 \%$ of the total metals in road runoff [2].

These toxic agents do not remain where they originate. They can be transported to different locations in a number of different ways. Some compounds can evaporate and drift away by winds before precipitating as rainfall. In addition, runoff from agricultural and urban areas into drainage pipes and sewers also contributes to significant pollution of surface and ground water. A study from Switzerland revealed that much of the rain in Europe contains high levels of dissolved pesticides, actually $4 \mu \mathrm{g} / \mathrm{l}$ of 2,4-dinitrophenol, and it would be illegal to supply this water for drinking purposes [3]. A field conditions study in Hungary revealed the presence of $154 \mu \mathrm{g} / \mathrm{l}$ of atrazine, $89.1 \mu \mathrm{g} / \mathrm{l}$ of acetochlor, $47.4 \mu \mathrm{g} / \mathrm{l}$ of propisochlor, and $0.139 \mu \mathrm{g} / \mathrm{l}$ of chlorpyrifos in runoff water [4].

Another significant part of environment contamination comes from the petrochemical industry. Typical petrochemical contaminants are hydrocarbons, alcohols, ketones, benzene derivatives (or BTEX), etc. Considering the adverse effects of the above pollutants on humans, animals, and wild life, the environmental agencies and World Health Organization set quite low limits (in the $0.1-0.5$-ppm range) for major heavy metals $(\mathrm{Hg}, \mathrm{Pb})$, pesticides (DDT, DDE, TDE, etc.), and petrochemicals (methyl alcohol and BTEX) pollutants in water, food, and feed [5]. 
The detection of the above environmental pollutants in such low concentration is quite a difficult task, though not impossible, and can be achieved with the existing advanced analytical methods such as atomic absorption or atomic emission spectroscopies (AAS, AES), inductively coupled plasma mass spectroscopy (ICP-MS), cold vapor atomic fluorescence spectroscopy (CVAFS), and high-performance liquid chromatography (HPLC). Those methods are extremely sensitive but expensive, requiring specialized laboratory conditions and highly trained personnel [6-9]. As a result, both the time and cost of analysis become very high.

An alternative approach to those high-tech methods is based on the use of biosensors, which could be much simpler, easy to use, and inexpensive. The main problem of biosensors, however, is the selection of bio-receptors which actually provide the function of recognition of target analyte molecules. Typical bio-receptors used in biosensors, e.g., enzymes, antibodies, aptamers, and peptides, can easily provide such functionality [10]. However, the traditional biosensing approach may struggle with a difficult task of detecting a large number of pollutants in a complex natural environment because every analyte may require a specific receptor. As a result, a large sensor array is required to fulfill the task at least partially which may lead to a quite complex detection protocol and therefore to high cost of analysis.

One of the possible solutions to such problem is the use of inhibition biosensors, where the bio-receptor, typically an enzyme, is inhibited by particular pollutants. The selectivity of this process is rather poor since the enzyme can be inhibited by different pollutants. Obviously, a single inhibition sensor cannot identify the pollutant, but a sensor array can. A good example of such inhibition sensor array was an optical enzyme sensor array which was enabled for both identification and quantification of several heavy metals and pesticides [11]. Although the principle of such sensor array has been successfully proven, poor stability of enzymes used (urease and cholinesterase) was a serious drawback which prevented commercialization of such devices.

Living cells are particularly useful for the detection of traces of environmentally toxic compounds because these molecules or ions interfere with one or several internal biological processes in cells and may cause modification of the cell's activity [10]. Several attempts of using whole cells as bioreceptors in inhibition sensors were reported [12]. Generally, electrical or electrochemical methods are promising transducing technologies for heavy metal ion detection. For example, potentiometric measurements using ion-selective polymer membranes enable the detection of metal ions in submicromolar concentrations $[13,14]$; however, more versatile receptors have to be used for simultaneous detection of different types of analytes, e.g., pollutants.

Another possibility explored recently was the use of microorganisms as sensitive elements [15]. A previous study of optical and electrical properties of solutions of two types of bacteria (Escherichia coli and Deinococcus radiodurans) has first established a correlation between the optical density and electrical conductivity and the bacteria concentration in liquid samples, and then revealed a possibility of rapid detection of the types of pollutants (heavy metals and radionuclides) by their effect on bacteria concentration [16]. A recent study was focused on the detection of heavy metals using mostly electrochemical measurements of two types of bacteria (E. coli and Shewanella oneidensis) which were either free in solution or immobilized on the surface of the screenprinted gold electrodes [17]. The results were encouraging, and the sensors with immobilized bacteria were the most promising for the development of an inhibition sensor array.

This work focuses on further development of electrochemical inhibition sensor array for detection of heavy metals $\left(\mathrm{PbCl}_{2}\right.$ salt was used here), pesticides (atrazine), and petrochemicals (hexane) which uses three channels, e.g., three electrodes with different types of bacteria (E. coli, S. oneidensis, and Methylococcus capsulatus Bath) immobilized on the surface. The choice of bacteria was justified by their inhibition patterns by the analytes used; the details are given in the following section. The main detection technique in this work was cyclic voltammograms, while optical methods of optical density, fluorescence microscopy, and flow cytometry as well as cyclic voltammograms of bacteria solutions were used as complementary techniques helping to establish a correlation between the bacteria concentration and their optical and electrical properties.

\section{Materials and Methods}

\subsection{Bacteria Sample Preparation}

For this work, the following three types of bacteria have been chosen: (i) Escherichia coli (E. coli K12 strain) which belong to the gram-negative bacteria type, generally sensitive to different types of pollutants including heavy metals, pesticides, and hydrocarbons [18], (ii) Shewanella oneidensis (S. oneidensis MR-1 strain) which belong to the gramnegative bacteria and known to be tolerant to heavy metals [19] because of its bio-catalytic activity towards heavy metals [20], and (iii) methanotrophic (Methylococcus capsulatus Bath strain) gram-negative bacteria which thrive in the presence of some petrochemicals $[21,22]$ because of its biodegradation properties [23]. LB (Luria-Bertain) broth was used as a medium for E. coli [24], and S. oneidensis bacterial cell cultures, while $M$. capsulatus (Bath) were grown in NMS (nitrate mineral salts) medium [25]. All three types of bacteria and respective growth media as well as phosphate-buffered solution (PBS) were acquired from Sigma-Aldrich Co. Other chemicals, i.e., $\mathrm{PbCl}_{2}$ salt, atrazine, hexane, and poly L-lysine 
(PL1), were also purchased from Sigma-Aldrich Co. Several stages of bacterial cultivation were performed: firstly, cultivation of a specific strain of bacteria in Petri dish containing solid agar to be used as a bacteria source in future; secondly, adding single colony from cultivated bacteria into a sterile flask containing $50 \mathrm{ml}$ of LB liquid broth for E. coli and S. oneidensis or $50 \mathrm{ml}$ of NMS medium for Methylococcus capsulatus (Bath) strain; lastly, the bacterial culture flask was placed inside a shaking incubator operating at 150 -rpm shaking speed. The incubation temperatures were $30^{\circ} \mathrm{C}$ for Shewanella oneidensis and Methylococcus capsulatus, while $37^{\circ} \mathrm{C}$ for E. coli. Bacteria start growing after $16 \mathrm{~h}$ for E. coli, $24 \mathrm{~h}$ for Shewanella oneidensis, and 2 weeks for Methylococcus capsulatus (Bath). Bacteria in solution samples were then studied with optical and electrochemical methods.

The abovementioned bacteria were immobilized on the modified screen-printed gold electrodes surface via poly Llysine (PLl) [26], by incubating a 1:1000 mixture of PLl $(0.1 \mathrm{mg} / \mathrm{ml})$ with deionized water for $1 \mathrm{~h}$ at $37^{\circ} \mathrm{C}$. Then, bacteria were immobilized by dropping stock solutions of E. coli, M. capsulatus (Bath), or S. oneidensis on the modified electrodes, keeping it there for $1 \mathrm{~h}$, and then washing out nonbound bacteria with PBS. The electrodes with immobilized bacteria could be kept in a fridge at $4{ }^{\circ} \mathrm{C}$ for $24 \mathrm{~h}$ without compromising bacteria activity.

\subsection{Experimental Methodology}

To study the inhibition effects on the abovementioned bacteria by selected pollutants, e.g., $\mathrm{PbCl}_{2}$, atrazine, and hexane, their solutions of different concentrations $(0.1,1,10$, and $100 \mathrm{mM})$ were prepared by multiple dilution of $1 \mathrm{M}$ stock solution of each analyte dissolved in deionized water. Forty percent ethanol solution in water was used for dissolving hexane (it has to be mentioned that at $40 \%$, the presence of ethanol had no effect of all bacteria used). Liquid bacteria samples were mixed with these solutions in 1:1 ratio and kept incubated for $2 \mathrm{~h}$. The samples of immobilized bacteria were treated similarly by immersing them into required solutions of pollutants for $2 \mathrm{~h}$.

The effect of the above pollutants on the bacterial cultures was monitored and analyzed using three different optical experimental techniques: fluorescence microscopy, UV-visible spectrophotometry $\left(\mathrm{OD}_{600}\right)$, and flow cytometry.

Fluorescence microscopy measurements were performed using an Olympus-BX60 instrument, using liquid bacterial samples also stained with L7012 Live/Dead (L/D) BacLight Bacterial Viability Kit [26, 27]. Also, fluorescent microscopy measurements were carried out on samples of bacteria immobilized on screen-printed gold electrodes. The numbers of live and dead bacteria were manually counted within the images recorded.
The optical density $\left(\mathrm{OD}_{600}\right)$ of cultivated bacteria was examined before and after exposure to different concentrations of pollutants using an optical density photometer $6715 \mathrm{UV} /$ Vis spectrophotometer (JENWAY). These measurements were carried out at a $600-\mathrm{nm}$ wavelength and represent the losses of light due to scattering on bacteria.

Flow cytometry is a technique commonly used assessing the size and number of bacterial cells. Suspension of bacterial cells typically marked with fluorescent dyes is injected into the flow cytometer instrument where bacteria propagate through a narrow channel and are probed one-by-one by focused laser beams exciting fluorescence. The scattered light and fluorescence from each bacterium were recorded. Tens of thousands of cells can be quickly examined and the data gathered are processed by a computer and finally shown as a $2 \mathrm{D}$ graph representing the state (live or dead) of bacteria and their size $[27,28]$. A flow cytometer (BECTON-DICKINSON FACSCalibur instrument) was used for counting the percentage of live and dead bacteria after coloring bacteria samples with L7012 Live/Dead Bacterial Viability Kit, which is a mixture of (SYTO-9) green fluorescence nucleic acid stain and the red fluorescence nucleic acid stain, propidium iodide.

The electrochemical measurements, i.e., cyclic voltammograms (CVs), were carried out using DropSens gold screenprinted three-electrode assemblies (which include $\mathrm{Ag} / \mathrm{AgCl}$ reference electrode) and DropSens microSTAT 8400P potentiostat. CVs of both liquid bacteria samples and samples of immobilized bacteria were recorded in a voltage range from -0.5 to $+0.5 \mathrm{~V}$; these measurements were taken before and after treatment with each analyte (pollutant) at different concentrations.

\section{Results and Discussion}

\subsection{Optical Characterization}

Optical characterization of liquid bacteria samples is essential for studying the effect of pollutants on concentration of live bacteria in liquid samples. In contrast to our previous studies $[16,17]$ where the methods of fluorescence microscopy and optical density $\left(\mathrm{OD}_{600}\right)$ were used for characterization of liquid bacteria samples, in this work, we deployed fluorescent microscopy for characterization of bacteria immobilized on the surface of screen-printed gold electrode. Fluorescence microscopy images in Fig. 1 show the effect of $\mathrm{Pb}^{2+}$ ions on Shewanella oneidensis bacteria immobilized on modified screen-printed gold electrodes where live and dead bacteria appear as green and red spots, respectively [17]. It is clear that the exposure to $1 \mathrm{M}$ solution of $\mathrm{PbCl}_{2}$ salt for $2 \mathrm{~h}$ reduced the number of live bacteria (green spots) and increased the dead ones (red spots). Such experiments were carried out for all three types of bacteria and all analytes used. The results of 
Fig. 1 Fluorescence microscopy images of immobilized

Shewanella oneidensis bacteria before (a) and after (b) treatment with $\mathrm{PbCl}_{2}$ salt $(1 \mathrm{M})$ for $2 \mathrm{~h}$
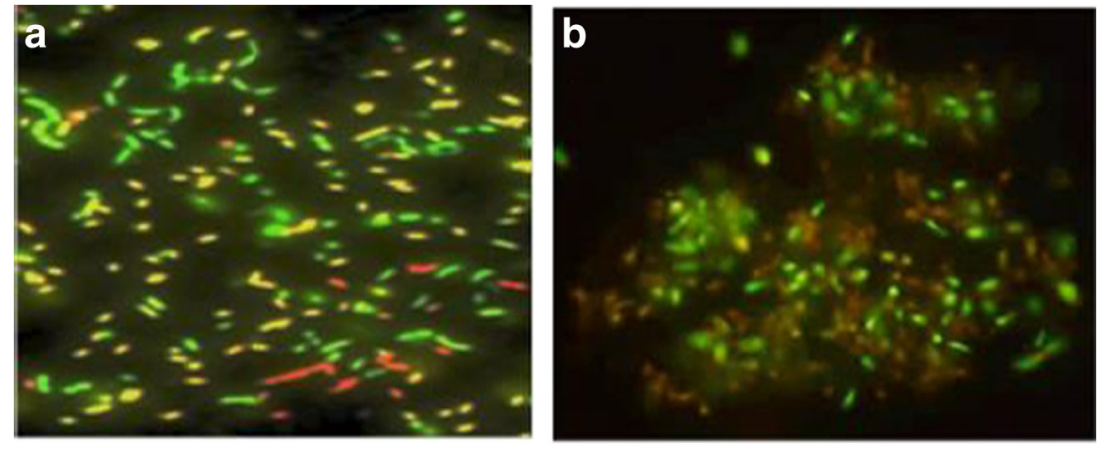

this study are presented in Table 1 as the numbers of live (green) and dead (red) bacteria on recorded images of identical dimensions.

Analysis of fluorescence microscopy data in Table 1 revealed that $E$. coli and M. capsulatus (Bath) are badly affected by large concentrations of $\mathrm{Pb}^{2+}$ ions, while $S$. oneidensis are less affected. The negative effect of atrazine is dramatic and more or less similar for all three bacteria. Hexane, however, did not affect $M$. capsulatus (Bath), though it inhibited both $E$. coli and $S$. oneidensis. Such a behavior of immobilized bacteria is similar to those bacteria in solution [17]. The study of optical density $\left(\mathrm{OD}_{600}\right)$ results of liquid bacteria samples in Fig. 2 shows the bacterial viability ratios (e.g., the ratios of live to dead bacteria) before and after treatment with large concentrations $(1 \mathrm{M})$ of $\mathrm{PbCl}_{2}$. The results are similar to those of fluorescent microscopy; all bacteria appeared to be affected by $\mathrm{PbCl}_{2}$ though this effect was less pronounced for S. oneidensis. It has to be said that the results of optical density measurements, which are based on light scattering, could be affected by different motilities of the bacteria studied.

The most accurate account of bacteria wellbeing can be obtained from flow cytometry measurements which combine the advantages of both fluorescence microscopy and optical density methods. Typical results of flow cytometry for all three bacteria before and after treatment with $1 \mathrm{M}$ solution of $\mathrm{PbCl}_{2}$ are presented in Fig. 3. In these experiments, bacteria were stained with L7012 Live/Dead Bacterial Viability Kit and appeared on the graphs in Fig. 3 as blue dots (for live bacteria) and orange dots (for dead bacteria). The increase in the dead bacteria counts after exposure to $\mathrm{PbCl}_{2}$ salt $(1 \mathrm{M}$ concentration for $2 \mathrm{~h}$ ) is visually apparent for all three types of bacteria studied.

In addition to that, after $\mathrm{PbCl}_{2}$ treatment, dead E. coli and M. capsulatus (Bath) bacteria appear mostly in the bottom-left quadrant of the graph in Fig. 3a and c, indicating the increase in the bacteria size is most likely due to hyper atrophy of cell membrane or rapture of cell walls. On the contrary, the size of $S$. oneidensis bacteria was affected much less by $\mathrm{PbCl}_{2}$; dead bacteria appeared slightly enlarged since they were shifted to the bottom-left in Fig. 3b.

Flow cytometry tests were carried out for the other two pollutants, e.g., atrazine and hexane, and the results are summarized in Table 2 as the percentage of live and dead bacteria.

Analysis of these data allowed us to conclude that E. coli bacteria are strongly inhibited by all three pollutants. $S$. oneidensis bacteria are less affected by $\mathrm{Pb}^{2+}$ ions as compared to the strong inhibition effect of atrazine and hexane. M. capsulatus (Bath) bacteria are badly affected by $\mathrm{Pb}^{2+}$ ions and atrazine, while hexane/ethanol mixture stimulates their growth.
Table 1 The numbers of live and dead bacteria immobilized on modified screen-printed gold electrodes for all three bacteria before and after treatment with $1 \mathrm{M}$ solutions of the three pollutants for $2 \mathrm{~h}$

\begin{tabular}{|c|c|c|c|c|c|}
\hline \multirow[t]{2}{*}{ Bacteria } & \multirow[t]{2}{*}{ Pollutants } & \multicolumn{2}{|c|}{ Before exposure } & \multicolumn{2}{|c|}{ After exposure } \\
\hline & & Live & Dead & Live & Dead \\
\hline Escherichia coli & $\mathrm{PbCl}_{2}$ & 93 & 20 & 21 & 65 \\
\hline Shewanella oneidensis & $\mathrm{PbCl}_{2}$ & 149 & 22 & 72 & 79 \\
\hline Methylococcus capsulatus (Bath) & $\mathrm{PbCl}_{2}$ & 43 & 13 & 16 & 57 \\
\hline Escherichia coli & Atrazine & 81 & 25 & 18 & 64 \\
\hline Shewanella oneidensis & Atrazine & 79 & 18 & 15 & 77 \\
\hline Methylococcus capsulatus (Bath) & Atrazine & 62 & 17 & 19 & 51 \\
\hline Escherichia coli & Hexane & 69 & 21 & 20 & 87 \\
\hline Shewanella oneidensis & Hexane & 57 & 11 & 28 & 62 \\
\hline Methylococcus capsulatus (Bath) & Hexane & 75 & 19 & 71 & 14 \\
\hline
\end{tabular}




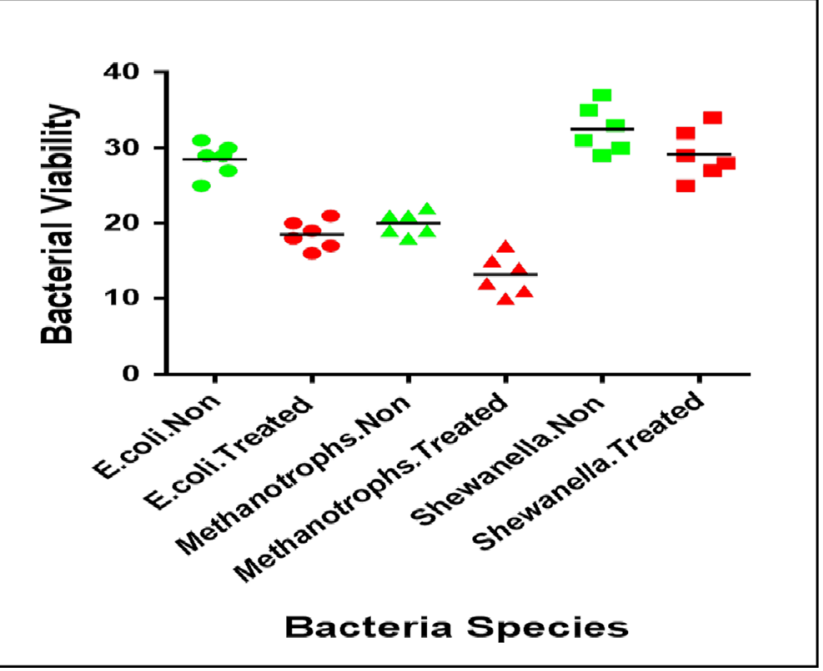

Fig. 2 Optical density $\left(\mathrm{OD}_{600}\right)$ data obtained for three bacteria solutions before and after treatment with $1 \mathrm{M}$ solution of $\mathrm{PbCl}_{2}$ for $2 \mathrm{~h}$

Among the three optical methods used to determine the live and dead bacteria percentage, flow cytometry appeared to be the most reliable and not affected by different motilities of E. coli, M. capsulatus (Bath), and S. oneidensis bacteria. The dead bacteria are not motile and tend to sediment which may affect the results of static fluorescent microscopy and optical density measurements. Nevertheless, the results of optical characterization of bacteria samples provided a background for further study using much simpler electrochemical method.

\subsection{Electrochemical Study of Bacteria in Solution and Immobilized Bacteria Samples}

In this work, the effect of $\mathrm{Pb}^{2+}$ ions, atrazine, and hexane on cyclic voltammograms (CVs) of all three bacteria, in both bacteria solutions and immobilized bacteria, was studied. Typical series of CVs recorded on E. coli, $S$. oneidensis, and M. capsulatus (Bath) samples are shown in Fig. 4. The graphs of CV in Fig. 4 are almost featureless in the selected voltage range from -0.5 to + $0.5 \mathrm{~V}$, which was chosen deliberately in order to avoid electrochemical reactions on the electrodes, with both cathodic and anodic currents just beginning to rise. The values of both cathodic and anodic currents at $-0.5 \mathrm{~V}$ and $+0.5 \mathrm{~V}$, respectively, depend on the bacteria concentration in solution [16, 17]; however, the effect on anodic current is more pronounced and it is therefore used for analysis in this work. The experiments are repeated several (3 to 5) times and show similar results.

In Fig. 4, CV cycles appear to shift upwards upon increasing the pollutant concentration from 0 (untreated bacteria) to $0.1 \mathrm{mM}, 1 \mathrm{mM}, 10 \mathrm{mM}, 100 \mathrm{mM}$, and $1 \mathrm{M}$. The characteristic parameter in this study, e.g., the value of anodic current at $+0.5 \mathrm{~V}$, increases with the increase in pollutant concentration for all three bacteria in both liquid and immobilized forms. This means that the electrical conductivity is controlled by bacteria adsorbed on the surface of screen-printed gold electrodes and acting as an insulating layer reducing the current. The correlation between bacteria concentration and the electric current (or conductivity) values is very important for further studying the effect of pollutants, and such measurements were always carried out first $[16,17]$. The presence of pollutants $\left(\mathrm{Pb}^{2+}\right.$ ions, atrazine, and hexane in our case) causes the damage of bacteria cells, and therefore bacteria became less insulating, in turn leading to the increase in the anodic current, which is observed in Fig. 4.

To analyze the effect of pollutants on electrical properties of immobilized bacteria, the values of anodic current $\left(I_{\mathrm{A}}\right)$ at + $0.5 \mathrm{~V}$ from $\mathrm{CV}$ measurements were normalized by the currents values of uncoated electrodes in PBS with the addition of a particular pollution of particular concentrations $\left(I_{\mathrm{A} 0}\right)$ to construct the values of relative changes of anodic current $\Delta I_{\mathrm{A}} /$ $I_{\mathrm{A} 0}=\left(I_{\mathrm{A}}-I_{\mathrm{A} 0}\right) / I_{\mathrm{A} 0}$. For example, for $S$. oneidensis bacteria treated with $1 \mathrm{mM}$ solution of $\mathrm{PbCl}_{2}$ (Fig. 4f), the reference was recorded on uncoated electrodes in PBS containing $1 \mathrm{mM}$ of $\mathrm{PbCl}_{2}$.

The relative changes in anodic current are presented in Fig. 5 for all three bacteria studied as concentration dependences of the three pollutants. As one can see, the effects of $\mathrm{PbCl}_{2}$, atrazine, and hexane on S. oneidensis, $M$. capsulatus (Bath), and E. coli are completely different. E. coli appeared to be affected by $\mathrm{PbCl}_{2}$, atrazine, and hexane even at low concentrations since the $\Delta I_{\mathrm{A}} / I_{\mathrm{A} 0}$ values increase monotonically in Fig. 5a, b, and c, respectively. This means that $E$. coli is equally inhibited by all three pollutants and becoming less electrically resisting. In contrast, $S$. oneidensis is almost unaffected by $\mathrm{PbCl}_{2}$ at low concentrations of all pollutants up to $10 \mathrm{mM}$, and then $\Delta I_{\mathrm{A}} / I_{\mathrm{A} 0}$ started to increase at high concentrations of $100 \mathrm{mM}$ and $1 \mathrm{M}$. Such a behavior of immobilized E. coli and $S$. oneidensis bacteria is similar to those free in liquid as reported in [17]. M. capsulatus (Bath) respond to $\mathrm{PbCl}_{2}$ (Fig. 5a) and atrazine (Fig. 5b) similarly to the other two bacteria studied though the changes in $\Delta I_{\mathrm{A}} / I_{\mathrm{A} 0}$ are more pronounced at high concentrations, particularly for atrazine. However, M. capsulatus (Bath) bacteria are not affected by hexane (see Fig. 5c) even at high concentration; moreover, an overall trend to small decrease in $\Delta I_{\mathrm{A}} / I_{\mathrm{A} 0}$ is observed. Such a behavior was expected since M. capsulatus (Bath) consume some hydrocarbons [25].

The results presented in Fig. 5 show a possibility of pattern recognition of the effect of the three pollutants studied. An attempt of pattern recognition has been done by presenting the relative responses of the three channels, e.g., three bacteria (E. coli, M. capsulatus (Bath), and 

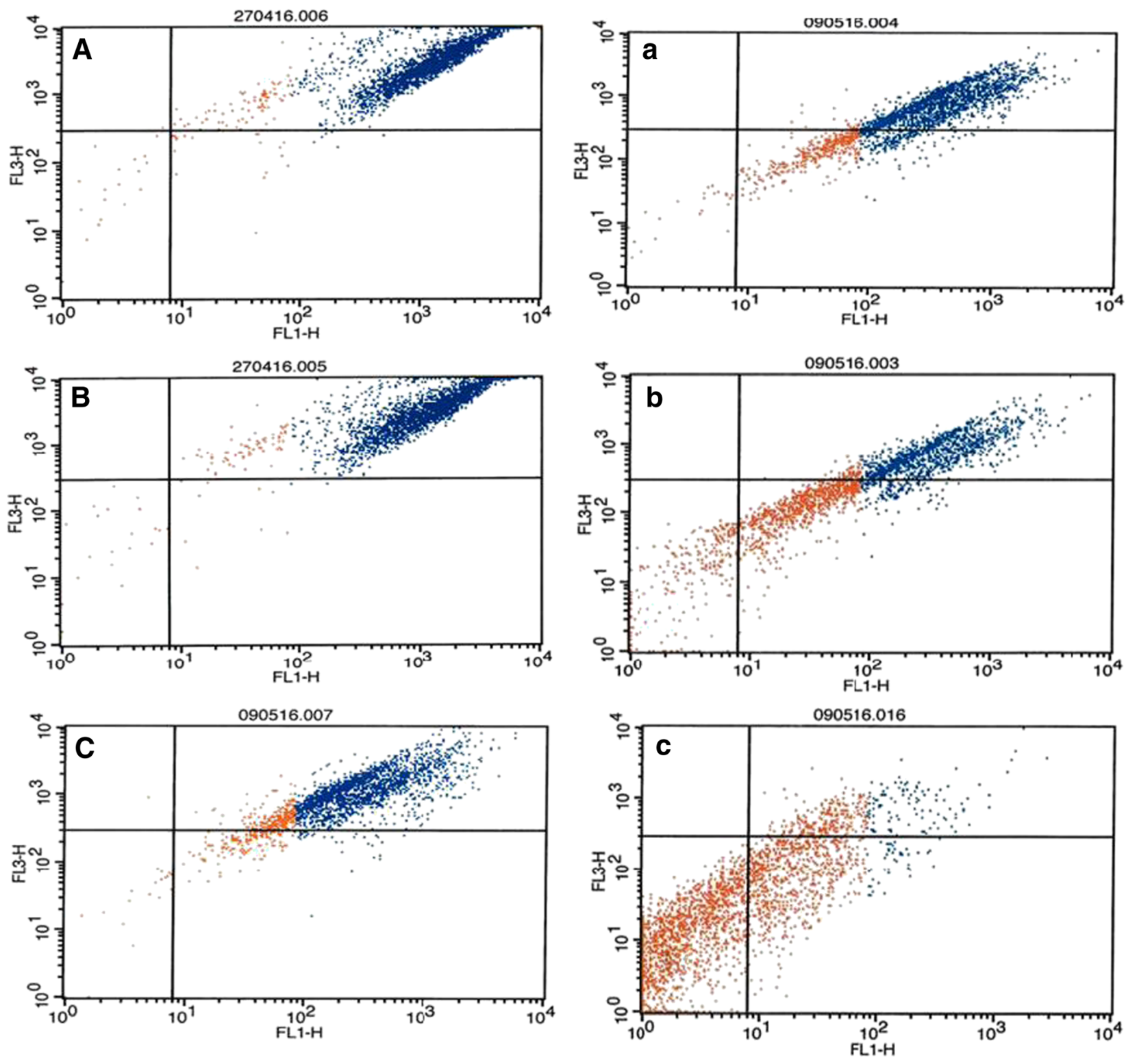

Fig. 3 Flow cytometry results for $S$. oneidensis $(\mathbf{A}), E$. coli $(\mathbf{B})$, and $M$. capsulatus Bath $(\mathbf{C})$ before (left) and after (right) treatment with $\mathrm{PbCl}_{2}(1 \mathrm{M}$ for $2 \mathrm{~h})$

S. oneidensis) immobilized on three screen-printed electrodes, to the three pollutants $\left(\mathrm{PbCl}_{2}\right.$, atrazine, and hexane) in a pseudo-3D plot in Fig. 6 .

The experimental points for $\mathrm{PbCl}_{2}$, atrazine, and hexane in concentrations up to $100 \mathrm{mM}$ shown in different colors are well-separated in this 3D graph. This is a clear indication that pattern recognition principles can be applied for identification of pollutants using different types of bacteria. The concentration of pollutants could be evaluated too using the appropriate calibration and data extrapolation.

\subsection{Discussion of the Results of Optical and Electrochemical Study}

The observed effects of the above pollutants on the three selected bacteria are somehow expected. In general terms, different chemicals of both organic and inorganic origin may affect microorganisms in two possible ways, e.g., acting as either catalyzers enhancing bacterial metabolism or as inhibitors having an opposite effect of reducing bacteria metabolism and even damaging bacteria membranes and causing their death. 
Table 2 Flow cytometry data: the percentage of live and dead bacteria before and after treatment with different pollutants

\begin{tabular}{|c|c|c|c|c|c|}
\hline \multirow[t]{2}{*}{ Type of bacteria } & \multirow[t]{2}{*}{ Type of pollutants } & \multicolumn{2}{|l|}{ Before } & \multicolumn{2}{|l|}{ After } \\
\hline & & Live $(\%)$ & $\operatorname{Dead}(\%)$ & Live $(\%)$ & Dead $(\%)$ \\
\hline Escherichia coli & $\mathrm{PbCl}_{2}$ & 61.88 & 38.12 & 28.11 & 71.89 \\
\hline Shewanella oneidensis & $\mathrm{PbCl}_{2}$ & 74.32 & 25.68 & 55.68 & 44.32 \\
\hline Methylococcus capsulatus (Bath) & $\mathrm{PbCl}_{2}$ & 65.49 & 33.51 & 36.49 & 63.51 \\
\hline Escherichia coli & Atrazine & 78.43 & 21.57 & 18.43 & 81.57 \\
\hline Shewanella oneidensis & Atrazine & 84.32 & 15.68 & 58.71 & 41.29 \\
\hline Methylococcus capsulatus (Bath) & Atrazine & 77.33 & 22.67 & 37.33 & 62.67 \\
\hline Escherichia coli & Hexane & 70.54 & 29.46 & 30.54 & 69.46 \\
\hline Shewanella oneidensis & Hexane & 88.71 & 11.29 & 45.68 & 54.32 \\
\hline Methylococcus capsulatus (Bath) & Hexane & 56.47 & 43.53 & 65.58 & 34.42 \\
\hline
\end{tabular}

In our case, E. coli is obviously inhibited by the pollutants used. This results in the reduction of live bacteria concentration which was confirmed by optical study. Consequently, the increased number of damaged or dead bacteria reduces their insulating properties, thus causing an increase in both anodic and cathodic currents.

Shewanella oneidensis bacteria are known to be tolerant to heavy metals in low concentration, which may have even growth-stimulating (catalytic) effects [20], which can be used in water treatment [29]; high concentrations of heavy metals are damaging. This explains the observed immunity of $S$. oneidensis to heavy metals at low concentrations, while other pollutants are still acting as inhibitors. M. capsulatus (Bath), in contrast, are known by their abilities to use some organic chemicals (hydrocarbons, alcohols) as food [23], and therefore are used in sewage treatment [30]. In other words, M. capsulatus (Bath) bacteria are catalyzed by some petrochemicals, while heavy metals and pesticides are still acting as inhibitors. The optical and electrochemical study of both $S$. oneidensis and M. capsulatus (Bath) showed the characteristic changes, respectively, in the live bacteria concentration and anodic current in line with their expected catalytic inhibition patterns.

Combining the above three types of bacteria in a sensor array was logical and therefore enabled the array to identify the type of pollutants. This could be achieved using optical methods with flow cytometry being perhaps the most suitable method for this task. However, very simple electrochemical measurements of anodic current could do a similar job at a substantially reduced cost. Modified screen-printed electrodes with immobilized bacteria can be prepared in advance and kept active for few weeks when stored in a fridge. Such electrical tests can be used for quick preliminary analysis of water samples; the samples indicating a presence of certain pollutants can be passed to specialized laboratories further for more detailed and accurate testing. The overall cost and time of analysis will be substantially reduced as a result.
The sensor stability depends on the activity of immobilized bacteria. We found that bacteria were still alive and active after 24-h storing in the fridge $\left(4^{\circ} \mathrm{C}\right)$, and after $48 \mathrm{~h}$, the live bacteria concentration slightly $(10-15 \%)$ reduced, and after $72 \mathrm{~h}$, reduced further to over $50 \%$. Therefore, we can conclude that currently the sensor stability is limited by $24 \mathrm{~h}$. Ideally, the electrodes with freshly immobilized bacteria have to be used for sensing.

\section{Conclusions and Future Work}

The effect of different types of pollutants, heavy metals ions $\left(\mathrm{Pb}^{2+}\right)$, pesticides (atrazine), and petrochemicals (hexane) on three types of bacteria, E. coli, M. capsulatus (Bath), and $S$. oneidensis, was studied using three different optical techniques: fluorescent microscopy and flow cytometry which yields directly the ratio of live/dead bacteria, stained, respectively, with "green" and "red" fluorescent dyes and optical density measurements at $600 \mathrm{~nm}$. All three optical methods are capable of detecting the effect of heavy metals, pesticides, and hydrocarbons on the above bacteria, though the flow cytometry is much more reliable. Fluorescent microscopy, however, which can be also carried out on immobilized bacteria provides a very useful link to the following electrochemical study. The results obtained were encouraging; however, the use of expensive and bulky optical instrumentation is not the way forward for portable and cost-effective sensor development.

Simple electrochemical tests, e.g., cyclic voltammograms, either on screen-printed gold electrodes immersed into liquid bacteria samples or (even better) on modified screen-printed gold electrodes with immobilized bacteria appeared to be very successful. The values of anode current were found to correlate with bacteria concentration and thus with the concentration of different pollutants 

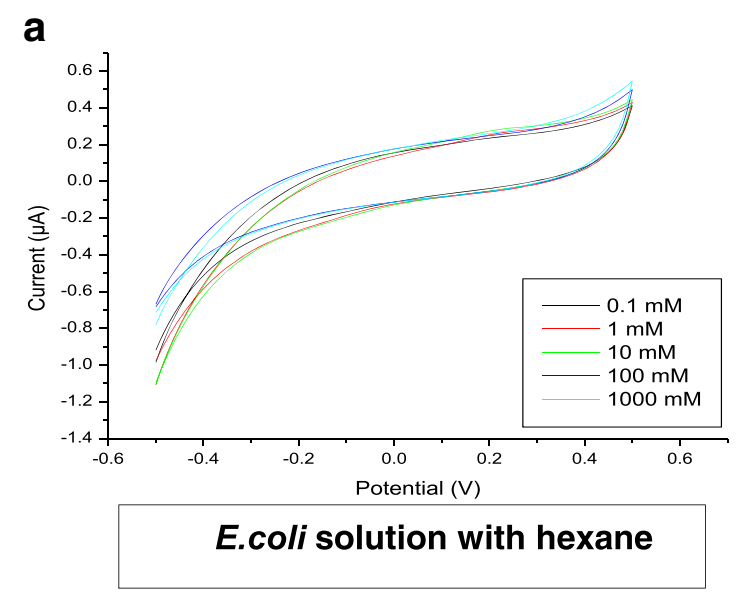

C
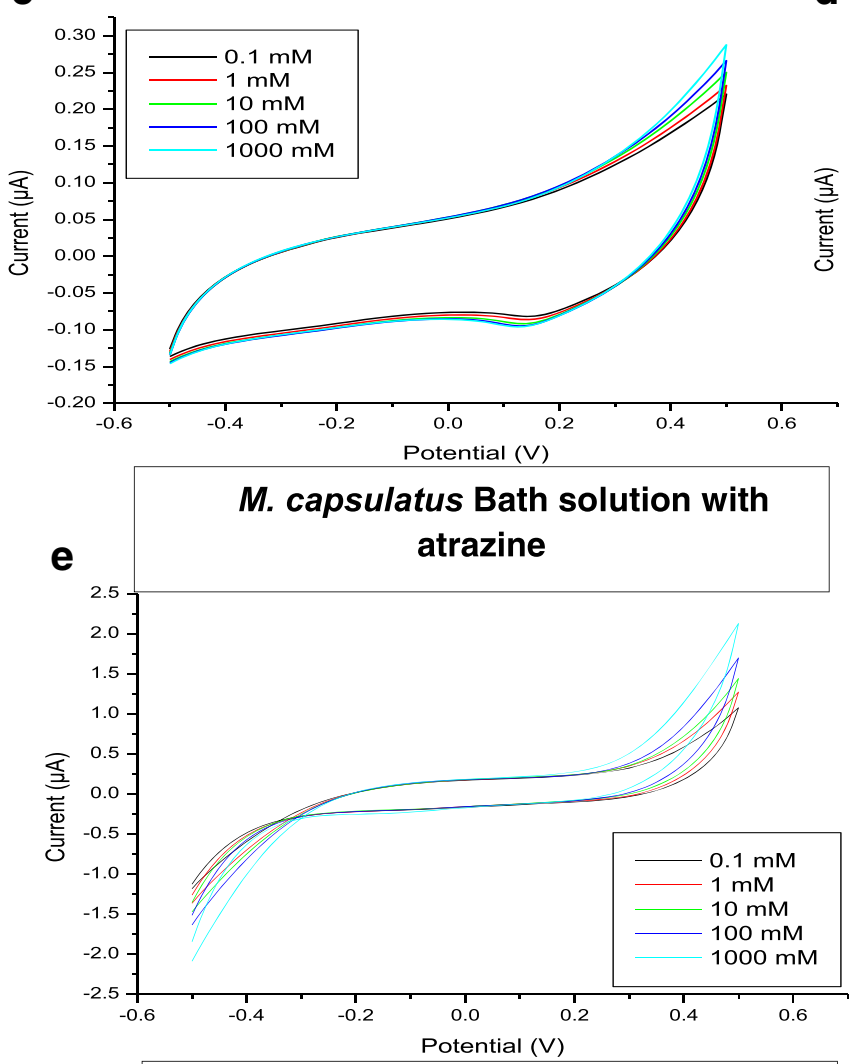

S. oneidensis solution with $\mathrm{PbCl}_{2}$
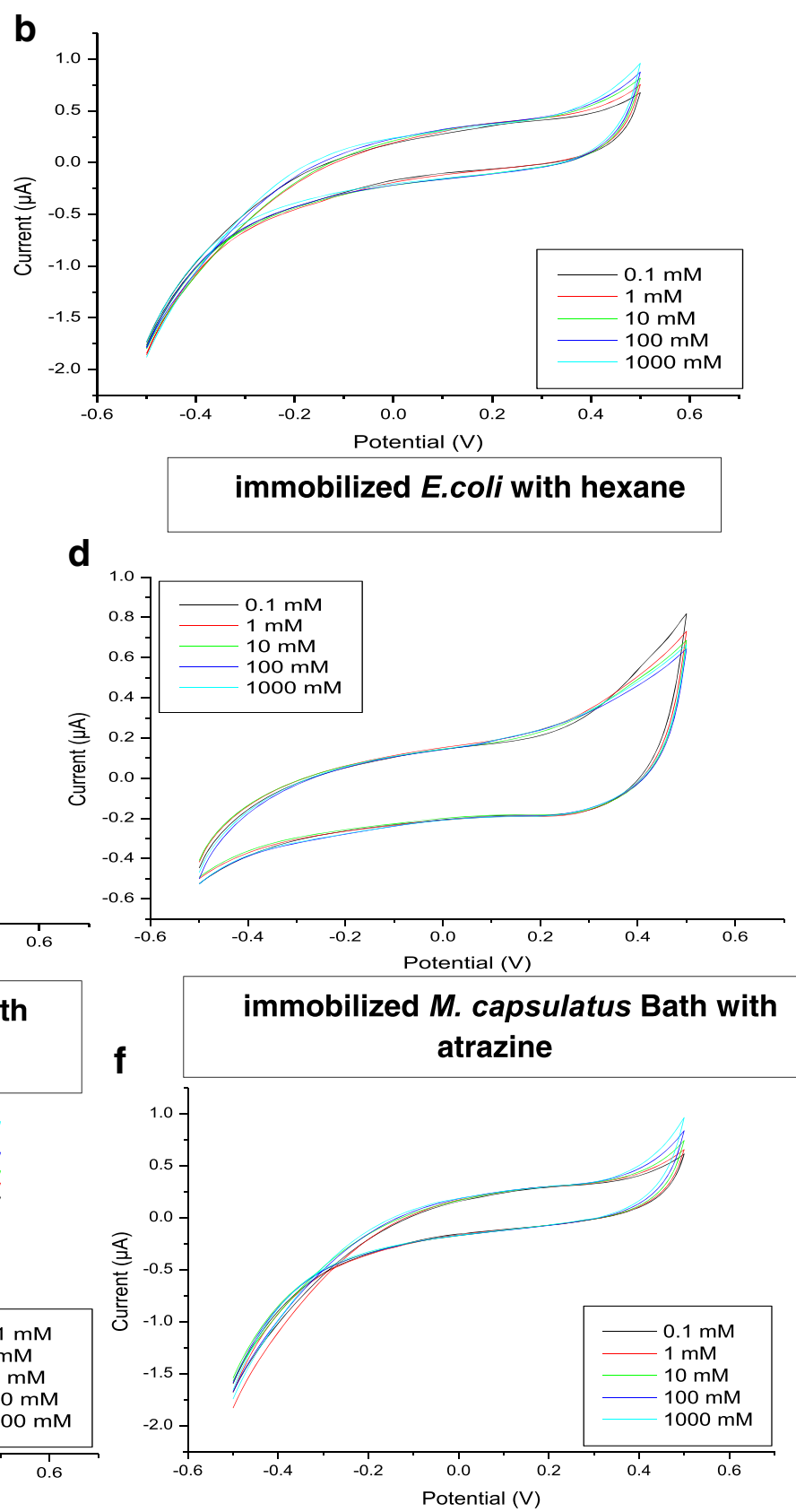

immobilized $\mathrm{S}$. oneidensis with $\mathrm{PbCl}_{2}$

Fig. 4 Cyclic voltammograms for: E. coli in solution (a) and immobilized E. coli (b) treated with hexane; M. capsulatus Bath in solution (c) and immobilized M. capsulatus Bath (d) treated with atrazine; and $S$. oneidensis in solution (e) and immobilized $S$. oneidensis $(\mathbf{f})$ treated with $\mathrm{PbCl}_{2}$

acting as inhibitors for bacteria. The effect of different pollutants on the three bacteria used was different: $E$. coli is strongly inhibited, while $S$. oneidensis is practically unaffected in a wide concentration range of all pollutants used. M. capsulatus (Bath) is strongly inhibited by $\mathrm{PbCl}_{2}$ and atrazine but completely unaffected by hexane. These facts opened a possibility of exploiting the principles of pattern recognition for identification of pollutants.
This work paves the way for the development of novel, simple, and cost-effective electrochemical bacteria-based sensor array for preliminary assessment of the presents of pollutants in water. Future work which is currently underway will focus on extending the range of pollutants (different heavy metals, pesticides, and petrochemicals) and using advanced data processing tools such as (ANN) artificial neural network for analysis of real water samples. 

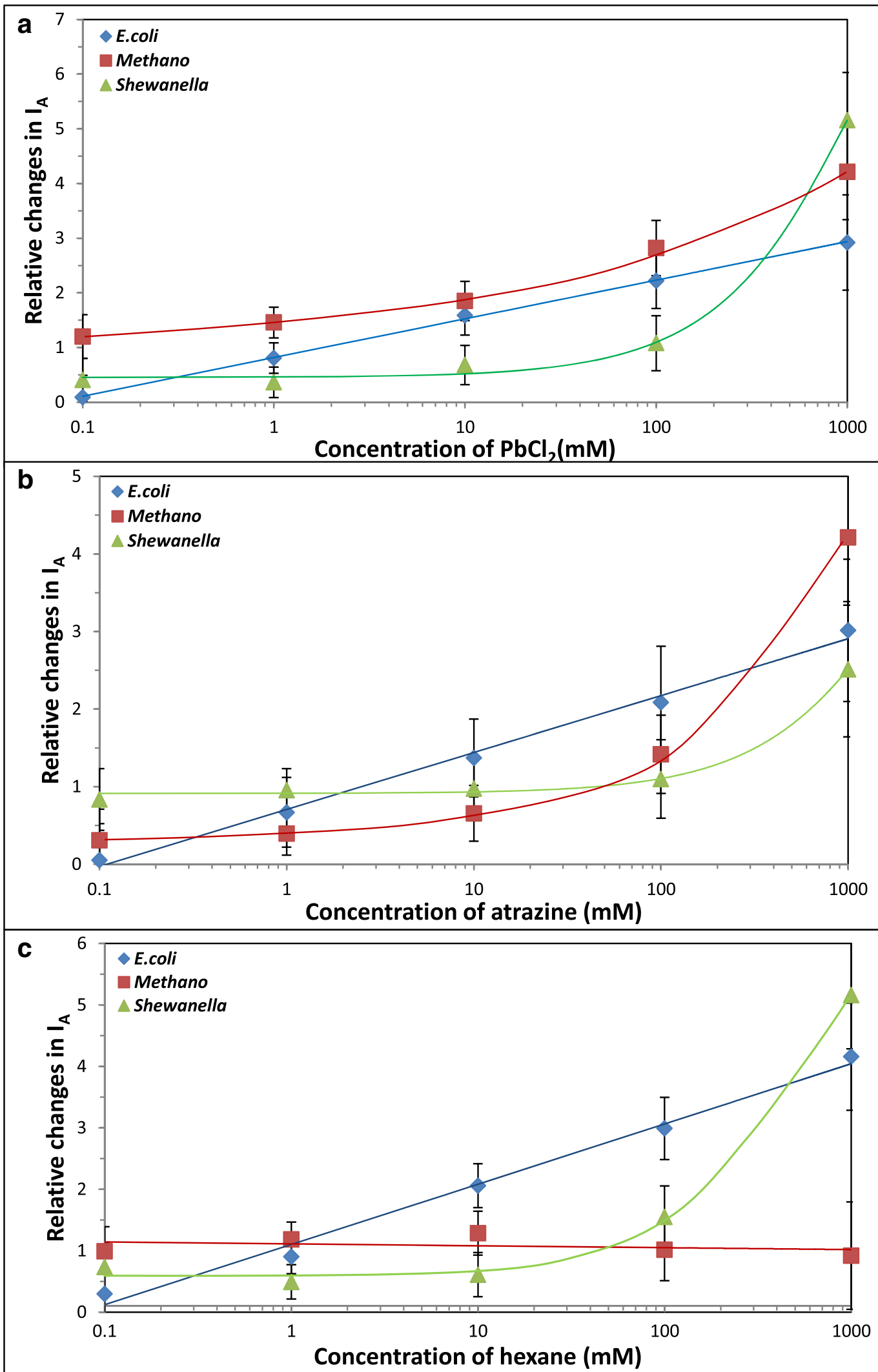

Fig. 5 Comparison of relative changes of anodic current $\left(I_{\mathrm{A}}\right)$ at $+0.5 \mathrm{~V}$ of all three types immobilized bacteria samples on modified electrodes exposure to $\mathrm{PbCl}_{2}(\mathbf{a})$, atrazine (b), and hexane (c) 
Fig. 6 3D plot of relative changes in anodic current for E. coli, M. capsulatus Bath, and $S$. oneidensis caused by different pollutants. Arrows show the direction of the pollutants' concentration increase from 0.1 to $100 \mathrm{mM}$

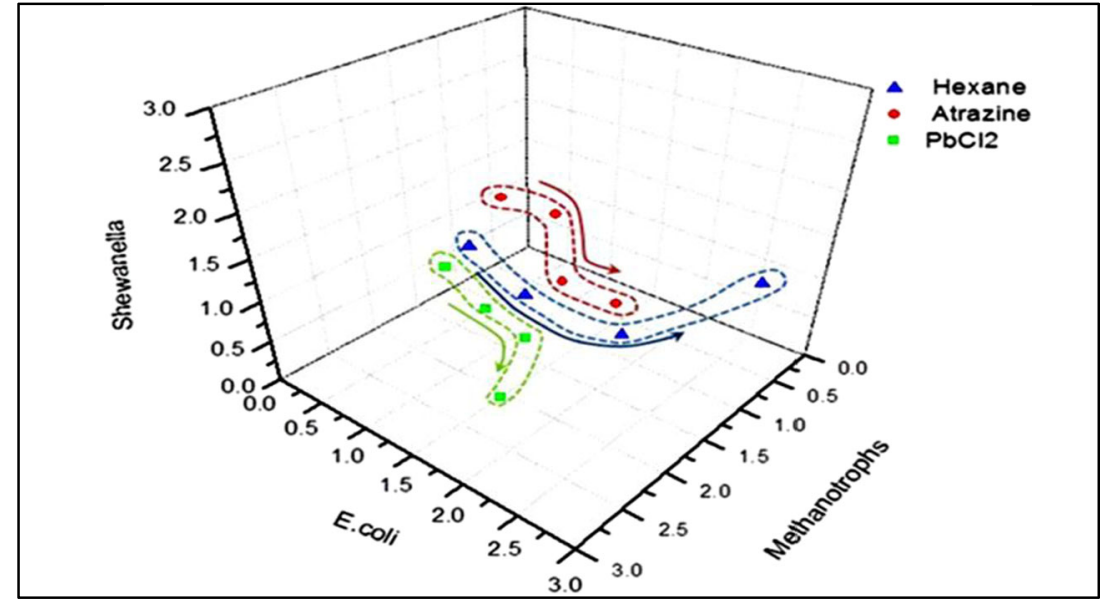

Acknowledgments The authors would like to thank the Iraqi Government, Ministry of Higher Education, and Scientific Research and University of Basrah for sponsoring the $\mathrm{PhD}$ project.

\section{Compliance with Ethical Standards}

Conflict of Interest The authors declare that they have no conflict of interest.

Open Access This article is distributed under the terms of the Creative Commons Attribution 4.0 International License (http:// creativecommons.org/licenses/by/4.0/), which permits unrestricted use, distribution, and reproduction in any medium, provided you give appropriate credit to the original author(s) and the source, provide a link to the Creative Commons license, and indicate if changes were made.

Publisher's Note Springer Nature remains neutral with regard to jurisdictional claims in published maps and institutional affiliations.

\section{References}

1. Ritter, K. S., Sibley, P., Hall, K., Keen, P., Mattu, G., \& Beth Linton, L. (2002). Sources, pathways, and relative risks of contaminants in surface water and groundwater: a perspective prepared for the Walkerton inquiry. Journal of Toxicology and Environmental Health Part A, 65(1), 1-142.

2. Walter, I., Martinez, F., \& Cala, V. (2006). Heavy metal speciation and phytotoxic effects of three representative sewage sludges for agricultural uses. Environmental Pollution, 139(3), 507-514.

3. Pearce, F., \& Mackenzie, D. (1999). It's raining pesticides. New Scientist, 162(2180), 23.

4. Konda, L. N., \& Pásztor, Z. (2001). Environmental distribution of acetochlor, atrazine, chlorpyrifos and propisochlor under field conditions. Journal of Agricultural and Food Chemistry, 49, 38593863.

5. Environment Agency. (2017). Groundwater risk assessment for your environmental permit. Website: https://www.gov.uk/ guidance/groundwater-riskassessment-for-your environmentalpermit\#develop-your-conceptual-model. Accessed October 2017.

6. Evans, E. H., Day, J. A., Palmer, C. D., Price, W. J., Smith, C. M., \& Tyson, J. F. (2005). Atomic spectrometry update. Advances in atomic emission, absorption and fluorescence spectrometry, and related techniques. Journal of Analytical Atomic Spectrometry, 20(6), 562-590.

7. Montes-Bayon, M., DeNicola, K., \& Caruso, J. A. (2003). Liquid chromatography-inductively coupled plasma mass spectrometry. Journal of Chromatography A, 1000, 457-476.

8. Zhang, Y., \& Adeloju, S. B. (2015). Coupling of non-selective adsorption with selective elution for novel in-line separation and detection of cadmium by vapour generation atomic absorption spectrometry. Talanta, 137, 148-155.

9. Harrington, C. F., Clough, R., Drennan-Harris, L. R., Hill, S. J., \& Tyson, J. F. (2011). Atomic spectrometry update. Elemental speciation. Journal of Analytical Atomic Spectrometry, 26, 1561-1595.

10. March, G., Nguyen, T. D., \& Piro, B. (2015). Modified electrodes used for electrochemical detection of metal ions in environmental analysis. Biosensors, 5(2), 241-275.

11. Nabok, A., \& Haron, S. (2004). Registration of heavy metal ions and pesticides with ATR planar waveguide enzyme sensors. Applied Surface Science, 238(1), 423-428.

12. Farré, M., Kantiani, L., Pérez, S., \& Barceló, D. (2009). Sensors and biosensors in support of EU Directives. TrAC Trends in Analytical Chemistry, 28(2), 170-185.

13. Sokalski, T., Ceresa, A., Zwickl, T., \& Pretsch, E. (1997). Large improvement of the lower detection limit of ion-selective polymer membrane electrodes. Journal of the American Chemical Society, 119(46), 11347-11348.

14. Maj-Żurawska, M., Sokalski, T., Ostaszewska, J., Paradowski, D., Mieczkowski, J., Czarnocki, Z., \& Hulanicki, A. (1997). Carbonate ion selective electrodes with trifluoroacetophenone derivatives in potentiometric clinical analyser. Talanta, 44(9), 1641-1647.

15. Starodub, N. F., Katzev, A. M., Levkovetz, I. A., Goncharuk, V. V., Klimenko, N. A., \& Vakulenko, V. F. (2003). Biosensor based on the photoluminescent bacteria and its use for express control of water contamination by some surface active substances. Transducers, Solid-State Sensors, Actuators and Microsystems, 12th International Conference IEEE Sensors , 2, 1197-1200.

16. Al-Shanawa, M., Nabok, A., Hashim, A., Smith, T., \& Forder, S. (2013). Detection of ionization radiation effect using microorganism (Escherichia coli). Sensors \& their applications XVII, Journal of Physics Conference Series 450 (012025). https://doi.org/10. 1088/1742-6596/450/1/012025.

17. Abu-Ali, H., Nabok, A., Smith, T., \& Al-Shanawa, M. (2017). Development of electrochemical inhibition biosensor based on bacteria for detection of environmental pollutant. Sensing and BioSensing Research, 13, 109-114. https://doi.org/10.1016/j.sbsr. 2016.10.007. 
18. Lăzăroaie, M. M. (2010). Multiple responses of gram-positive and gram-negative bacteria to mixture of hydrocarbons. Brazilian Journal of Microbiology, 41(3), 649-667.

19. Ramírez-Díaz, M. I., Díaz-Pérez, C., Vargas, E., Riveros-Rosas, H., Campos-García, J., \& Cervantes, C. (2008). Mechanisms of bacterial resistance to chromium compounds. Biometals, 21(3), 321332.

20. Carmona-Martinez, A. A., Harnisch, F., Fitzgerald, L. A., Biffinger, J. C., Ringeisen, B. R., \& Schröder, U. (2011). Cyclic voltammetric analysis of the electron transfer of Shewanella oneidensis MR-1 and nanofilament and cytochrome knock-out mutants. Bioelectrochemistry, 81(2), 74-80.

21. Leak, D. J., \& Dalton, H. (1986). Growth yields of methanotrophs. Applied Microbiology and Biotechnology, 23(6), 470-476.

22. Han, J. I., Lontoh, S., \& Semrau, J. D. (1999). Degradation of chlorinated and brominated hydrocarbons by Methylomicrobium album BG8. Archives of Microbiology, 172(6), 393-400.

23. Hanson, R. S., \& Hanson, T. E. (1996). Methanotrophic bacteria. Microbiological Reviews, 60(2), 439-471.

24. Sezonov, G., Joseleau-Petit, D., \& D’Ari, R. (2007). Escherichia coli physiology in Luria-Bertani broth. Journal of Bacteriology, 189(23), 8746-8749.
25. Whittenbury, R., Phillips, K. C., \& Wilkinson, J. F. (1970). Enrichment, isolation and some properties of methane-utilizing bacteria. Microbiology, 61(2), 205-218.

26. Suo, Z., Avci, R., Yang, X., \& Pascual, D. W. (2008). Efficient immobilization and patterning of live bacterial cells. Langmuir, 24(8), 4161-4167.

27. Berney, M., Hammes, F., Bosshard, F., Weilenmann, H. U., \& Egli, T. (2007). Assessment and interpretation of bacterial viability by using the LIVE/DEAD BacLight Kit in combination with flow cytometry. Applied and Environmental Microbiology, 73(10), 3283-3290.

28. Kaprelyants, A. S., \& Kell, D. B. (1992). Rapid assessment of bacterial viability and vitality by rhodamine 123 and flow cytometry. Journal of Applied Microbiology, 72(5), 410-422.

29. Du, Z., Li, H., \& Gu, T. (2007). A state of the art review on microbial fuel cells: a promising technology for wastewater treatment and bioenergy. Biotechnology Advances, 25(5), 464-482.

30. Kampman, C., Hendrickx, T. L., Luesken, F. A., van Alen, T. A., den Camp, H. J. O., Jetten, M. S., \& Temmink, H. (2012). Enrichment of denitrifying methanotrophic bacteria for application after direct low-temperature anaerobic sewage treatment. Journal of Hazardous Materials, 227, 164-171. 